\title{
R Reserach S Suare \\ The Impact of Climate Change On Financing Cost of Heavy-Pollution Firms in China
}

Kai Chang ( $\square$ kchang16@163.com )

Shanghai Normal University

\section{Yixia Nie}

Guizhou University

\section{Research Article}

Keywords: temperature change, precipitation change, heavy-pollution firms, financing cost

Posted Date: December 1st, 2021

DOI: https://doi.org/10.21203/rs.3.rs-1075957/v1

License: (c) (i) This work is licensed under a Creative Commons Attribution 4.0 International License. Read Full License 


\section{Abstract}

We examines the effects of climate change on the financing cost of heavy-pollution firms using firm-level panel data analysis. The empirical results demonstrate that the annual temperature and precipitation changes can significantly promote the financing costs of heavy-pollution firms, the positive impacts of annual temperature and precipitation changes on the financing costs of large, medium and small heavypollution firms has shown a gradual weakening trend with an increase of firm size, and the positive effects of annual temperature and precipitation changes on the financing costs of younger and older heavy-pollution firms has shown a decline trend with an increase of firm age. The evidences confirms that the impact of climate change on the financing costs of heavy-pollution firms exhibit a significant firm size and age discrimination of financing behaviors. Government decision-makers have to identify and optimize the transmission effect of climate change response on financing behavior decisions of heavy-pollution industries, financial institutions alleviate financial conflicts and credit discrimination behaviors and optimize the efficiency of financial resource allocation. Firms' executives correct climate change strategy, optimize the climate- relevant operation, investment and financing activities, and alleviate unfavorable influences of climate changes for heavy-pollution firms.

\section{Introduction}

In recent decade, the continuous increase of greenhouse gases has brought about global warming, and high-frequency and high-intensity extreme climate changes have brought huge challenges and disasters to human society and natural systems. For example, the melting of Antarctic glaciers has accelerated, forest fires in Australia have been burning for several months, Philippines has experienced continuous drought and the United States have experienced extremely cold temperatures. These extreme climate changes have brought about huge loss for human social and economic activities (Sequeira, et al.2018; Lu,et al.2019; Chen and Li,2020). Climate change is the most urgent long-term threat to human society. Global warming and extreme climate change directly or indirectly pose long-term risks to the regional economy and society development, which have received widespread attention from the international community. In 1992, the United Nations General Assembly adopted the "United Nations Framework Convention on Climate Change." Climate change is a global problem faced by global countries and regions. Global climate change is huge disasters to human society and ecosystems, which bring immeasurable economic losses to human society. On December 12, 2015, the Paris Climate Conference passed the "Paris Agreement", and on April 12, 2016, member states signed a climate change agreement in New York. The response to climate change requires stronger international cooperation and strengthens the response to climate change ability. In the World Economic Forum in Davos, Switzerland in January 2020, economists and business leaders from global politician, business leadership and economist recognized that addressing climate change is one of the most important challenges for human society. The Chinese government has issued annual reports on its policies and actions to address climate change for 11 consecutive years. China has achieved positive results in addressing climate change, its ability to respond to climate change has gradually increased, and industrial enterprises have 
continuously improved their awareness of addressing climate change. How to deal with climate change, coordinate the contradiction between economic development and greenhouse gas emission reduction, and achieve sustainable and inclusive growth are ever-increasing concerned problems for global countries and regions (Bakhsh,et al,2020;Mahmood, et al,2020; Lu,et al.2021).

The benefit-cost approach responding to climate change is a hot topic (Koomey,2013). In recent years, climate change may cause major damage to many firms, and eventually may induce firms boost their industrial activities to move away from those areas highly affected by climate change (Linnenluecke et al., 2011). Mitigating climate change and reducing related greenhouse gas emissions are challenges faced by a good many firms in the world. Firms and industries have a central role in the physical effects of climate change under supporting societal adaptation (Linnenluecke, et al.2013). Increasing climate change causes worktime and labor productivity reduction (Takakura,et al.2017). More and more firms are adopting climate-related emission reduction strategies and information disclosure to effectively respond to national climate change (Canevari,2020). The challenge of responding to global climate change is an important task for corporate strategic reforms, which force many firms to enhance their rationalization and strategic reforms, improves the utilization of their resources allocation, and thereby enhances firms' market competitiveness (Clark and Crawford, 2012; Tamošiūnas, 2014). Climate change is closely related to the daily operational process and financial performance for many firms. External stakeholders are concerned that the response to climate change will affect the daily operations of the firms' climate riskrelated processes, supervision, reputation and litigation risks (Sullivan and Gouldson, 2017). The exposure of to climate change can reflect firms' social responsibility actions that affect corporate market value and stock market response (Ziegler et al., 2011; Hsu and Wang, 2013). Different government commitments to address climate change will lead to significant differences in firm's market value and stock market portfolio risk (Berkman et al., 2019; Secinaro,et al.2020). In United States, industrial firms disclose that climate change-related performance did not significantly affect corporate operational efficiency and environmental efficiency, and carbon-intensive industrial firms perform better operational performance and higher response to climate change (Yu et al., 2016). Under the European Union carbon trading markets, the carbon-intensive firms widely adopt emission reduction strategies to address climate change (Sarasini, 2013; Cadez and Czerny, 2016;Wang and Sueyosh,2018). External agencies, stakeholders, and internal governance will pay much attention to the firms' strategy development to deal with climate change, the uncertainty of greenhouse gas regulation, and emission reduction strategies (Damert and Baumgartner, 2018; Cadez et al., 2019; Dahlmann et al., 2019). Climate variations are dependent on emission pathways (Nohara,et al.2013). The actions to address climate change and emission reduction strategies will directly affect firms' carbon emissions costs and their greenhouse gas emissions (Cadez and Guilding, 2017; Kennard,2020;Toft and Rüdiger,2020). Traditional knowledge, public policies and technological innovation may support financial policy and sustainable development (Li,et al.2021).

Climate change mitigation efforts are positively related with firm size, profitability, industry membership, government ownership and business network in Malaysia (Amran,et al.2012;Eleftheriadis and Anagnostopoulou,2015). State-owned firms and Chinese environmentally sensitive industries have 
greater efforts to disclose more information about $\mathrm{CO}_{2}$ emission (Kuo, et al.2015). Firms' carbon information disclosure cause the negative market reaction (Lee,et al.2015). Indian firms' climate change information disclosure has a significant positive correlation with returns on equity, and those firms with higher returns on equity will disclose more information about climate change (Praveen and Mohammad, 2018). Climate change activists' public and private politics ethics may elicit different organizational internal and external responses (Hiatt, et al.2015;Toft and Rüdiger,2020). Climate change information disclosure lead to better environmental performance (Giannarakis, et al.2018). Firms can carry out heterogeneous mitigation technologies portfolios, including pollution control, green design, eco-efficiency, low-carbon energy (Wang, et al.2018).

Responding to climate change will bring significant differences in the financial performance and risk impacts for firms in different industries. Extreme climate change events can lead to unsustainable business activities of industrial firms. The external environment and internal environment lead to large differences in climate change actions and development strategies of different firms, which affect the unfair resources allocation among different firms. Market investors gradually realize that addressing climate change may have a certain negative impact on the firm's financial performance in heavily polluting industries, alleviating the increase of climate -change-related costs and addressing climate change strategies. As China's strategy for addressing climate change will be integrated into the "Fourteenth Five-Year" National Economic and Social Development Planning and the Ecological Environment Protection Planning, China will continue to take active measures to control greenhouse gas emissions and strengthen the response to climate change, pollution prevention, and ecological environment. The comprehensive integration of protection has enabled firms in different industries to update their strategies and enhance their comprehensive capabilities to adapt to climate change. Heavypolluting industries are the most affected industries by climate change strategies. Different heavypolluting industries will also enhance strategic actions and capacity establishment to address climate change. Currently, many firms in heavy-pollution industries may face certain financing discrimination and financial frictions in their strategic actions to address climate change. Climate change will also affect the capital structure of enterprises in heavy-pollution industries and their related financing costs. Therefore, studying the impact of climate change on the financing costs of heavily pollution firms is an important core scientific issue in the process of tackling climate change. However, the current domestic and foreign literature rarely involves the relationship between climate change and firms' financing costs, this article fills the gaps of their correlations from the perspective of firm's size and age.

Carbon information disclosure level reduce the cost of equity financing ( $\mathrm{Li}$, et al.2017).The academic research on the relationship between climate change and financing cost of heavily-polluting firms is a brand-new scientific issue, and the statistical results of this paper have important scientific research value for government decision- makers, financial institutions and firm managers. There are three important innovative achievements in our study: First, this article selects 789 heavily polluting firms from 2008 to 2018 as the research objects, and analyzes the impact of annual temperature and precipitation changes on the financing costs of heavily-polluting firms using panel data analysis. The empirical results 
confirm that an increase of annual temperature and precipitation can significantly increase the financing costs of heavily polluting firms. Second, different firm sizes can significantly modiate the relationship between climate change and financing costs of heavily-polluting firms, an increase of annual temperature and precipitation may gradually alleviate their positive impacts of financing cost of heavily-polluting firms with the gradual increase of firm scale, especially the changes of temperature and precipitation are more sensitive to the impact of financing cost of small- and medium-sized heavily-polluting firms. Third, different firm ages can adjust the correlation between climate change and financing costs of heavilypolluting firms with the gradual increase of firm ages, the increase of annual temperature and precipitation may gradually alleviate their positive impacts of financing costs of heavily-polluting firms, especially climate changes are more sensitive to the impact of financing costs of younger heavilypolluting firms.

\section{Theoretical Analysis And Hypothesis Design}

Climate change will bring three related climate risks to firm's management: uncertainty of physical environment, uncertainty of regulatory policies and uncertainty of economic and financial activities. Extreme climate change urges heavily-polluting firms to adjust their strategies and adaptation actions to deal with climate change in a timely manner, which are mainly reflected in climate risks related to climate change, strategic awareness and organizational vulnerability to adapt to climate change, and their management actions and investment activities to deal with climate change.

Organizational vulnerability and strategic awareness of coping with climate change are considered to have the significant impacts on the adaptation strategy of heavily-polluting firms to climate change. First, persistent climate change, especially, extreme climate change with high frequency and intensity will bring some potential climate-related risks to heavily-polluting firms. Recognizing extreme climate change will bring serious damage to investment activities, production and operation activities, firm managers realize the vulnerability of firm's management to deal with climate change (such as the defects or lack of ability to deal with floods) will bring about economic losses(Mele, et al,2021), such as traffic congestion, logistics delay, local firms' sales losses etc. Second, the continuous extreme hot or severe cold causes heavy-polluting firms to generate higher electricity consumption, soaring energy prices and greater productivity losses after electricity shortage. The continuous increase of climate-related risks will bring higher economic losses and financial risks to heavy-polluting firms, which lead to an increase in debt financing costs of heavy-polluting firms. Continuous extreme temperature leads to the decline of employee's productivity and the decrease of resource allocation efficiency, which causes the increase of climate-related risks of financial friction and debt activities in heavy-polluting firms. These potential threats or adverse effects related to climate change urge heavy-polluting firms to enhance their strategic awareness of coping with climate change. Continuously increase business development and optimize operational processes related with climate change increase debt financing activities, then organization's market adaptability to climate change and the flexibility of its operation will be improved. Heavy-polluting firms continuously enhance investment activities and debt financing related to climate risks, which may lead to an increase of firms' debt financing costs. The Chinese governments have continuously supervise 
energy-saving and emission-reduction performance, and environmental regulation of heavy-polluting firms through multiple environmental regulatory policies, such as strict environmental laws and regulations, constraint targets for energy saving and emission reduction, environmental taxes and carbon trading scheme. Market investors tend to focus on those firms' financing cost, extreme climate change and strict environmental regulations make market investors believe higher financial risks of heavypolluting enterprises related to climate risks, which will reduce the investment opportunities and expected operating profit margins of heavy-polluting firms. Meantime, market investors obtain higher return on investment and increase the financing costs of heavy-polluting firms. From the analysis of agency theory, extreme climate change and stricter environmental regulation prompt firms' stakeholders to recognize higher climate risks and environmental regulation risks of heavy-polluting firms. As a result, financial institutions may have credit discrimination and market friction, heavy-polluting firms face greater uncertainty of cash flow management, which credit rating entities reduce the quality of firm's credit rating. An increase of heavy-polluting firms' financing costs enhance their awareness of environmental protection, timely adjustment of strategic actions to deal with climate change, improvement of firm's energy-saving and emission-reduction performance, and environmental pollutions (greenhouse gases, pollutants and sewage) improvement. Heavy-polluting firms increase the uncertainty of cash flow management and induce the increase of short-term debt activities and debt costs. Heavy-polluting firms try to reduce climate risks and environmental regulation risks related to climate change, then reduce agent problems and financing costs.

Hypothesis 1: Climate change has a significant positive impact on the financing cost of heavy-polluting firms.

Chinese banking system may have certain credit discrimination against heavy-polluting firm with different sizes when choosing credit loans. Extreme climate change brings different economic losses of heavy-polluting firms with different sizes, heavy-polluting enterprises enhance their ability to resist climate-related risks and improve their market adaptability to climate change with an increase of firm size. Meanwhile, climate change will bring heavy-polluting firms about the lower adverse impacts and effectively reduce their economic losses induced by extreme climate change. With an increase of firm size, if climate change bring about lower operating losses of larger heavy-polluting firms, financial institutions provide more favorable external financial resources, which are beneficial to reduce the financing costs of the larger heavy-polluting firms. Extreme climate change will induce the local governments carry out stricter environmental regulation intensity, increase the operating costs and reduce the market competitive advantage of heavy-polluting firms (Hsu and Wang, 2013;Lu,et al.2020). Financial institutions are worried that climate change will bring about greater uncertainty of the business activities, investment activities and market demand of heavy-polluting firms. Climate changes(such as drought, flood, high temperature and severe cold) have a significant negative impact on the business activities of heavy-polluting firms, also causes interruption or adverse effects on upstream and downstream resource suppliers and buyers of the industrial chain. Unexpected climate change will bring small and mediumsized heavy-polluting firms about greater economic losses, and then small and medium-sized heavypolluting firm obtain higher financing costs. 
Hypothesis 2: Climate change may reduce the impact on the financing cost of heavy-polluting firms with the gradual increase of firm scale.

Heavy-polluting firms with different firm age have different pressures from stakeholders, younger heavypolluting firms strive to improve the expected profits of heavy-polluting firms. To minimize the unfavorable factors induced by climate change, it is necessary heavy-polluting firm managers to raise greater external funds to optimize business the operational processes and market performance, to improve the market response speed related to climate change, which may lead to an increase of shortterm financing costs. With the gradual increase of firm age, Heavy-polluting firms prefer to raise greater external funds through capital markets in order to improve business processes and market adaptability related to climate change and reduce the external dependence on debt funds. Therefore, older heavypolluting firms can alleviate the pressure on the rising financing costs related to climate change. When financial institutions provide heavy-polluting firms external debt funds, they must consider the operating losses of heavy-polluting firms caused by firm age and climate change, and then provide appropriately correctness of the heavy-polluting firms' financing costs.

Hypothesis 3: Heavy-polluting firm age may moderate the relationship with climate change and financing costs.

\section{Econometric Model And Variable Explanation 3.1 Econometric model}

Generally, heavy-polluting firms constantly correct and adapt to the changing economic environment, but heavy-polluting firms seldom learn to adapt to the changes of climate environment. Heavy-polluting firms can endure seasonal climate and environmental changes, while extreme climate changes may cause heavy-polluting firms the vulnerability of coping with climate change, and the potential changes of extreme climate may exceed the market adaptability of heavy-polluting firms. Extreme climate changes will induce heavy-polluting firms their ability reduction of responding quickly to climate change, promote the mismatch between climate change and operation processes, and induce the decline of operation efficiency and expected profits of heavy-polluting firms. Rainfall changes will have a negative impact on the income of vineyard growers, while high temperature can make up the negative impact rainfall changes (Salvo et al., 2015). Extreme climate change may prompt industrial firms to migrate those regions with less impact of climate change (Linnenluecke et al., 2011), and also affect the operational efficiency and financial value of industrial firms (Yu et al., 2016; Lucas and Silva, 2018; Berkman et al., 2019). In order to investigate the impact of temperature and precipitation changes on the financing costs of heavy-polluting firms, this aritcle constructs panel data econometric model according to Hypothesis 1 as follows:

$D F C_{i t}=c+a_{1} C D_{i t}+a_{2} A T_{i t}+\beta_{7} Q_{i t}+\beta_{2}$ size $_{i t}+\beta_{3} g r o w_{i t}+\beta_{4} g s_{i t}+\beta_{5} C O_{i t}+\beta_{6} b s_{i t}+\beta_{7} a g e_{i t}+\xi_{i t}(1)$ 
In Equation (1), $\mathrm{DFC}$ it is the cost of debt financing, $\mathrm{CD}_{i \mathrm{t}}, \mathrm{AT}_{\mathrm{it}}$ are the annual average temperature change rate and the annual precipitation change rate respectively, $Q_{i t}, \operatorname{size}_{i t}, g r o w_{i t}, g s_{i t}, c o_{i t}, b s_{i t}, a g e_{i t}$ are firm market value, firm size, growth, liquid asset ratio, ownership concentration, board of director size and firm age respectively. $a_{1}, \alpha_{2}$ are the coefficient of the annual temperature change ratio and annual precipitation change ratio, $\beta_{1} \sim \beta_{7}$ are the coefficients of relevant control variables, and $\xi_{i t}$ is the residual error. In order to investigate whether firm size can moderate the relationship between climate change and the financing cost of heavy-polluting firms according to Hypothesis 2, we construct the following model:

$D F C_{i t}=c+a_{1} C D_{i t} \times$ size $_{i t}+a_{2} A T_{i t} \times$ size $_{i t}+\beta_{7} Q_{i t}+\beta_{2}$ grow $_{i t}+\beta_{3} g s_{i t}+\beta_{4} c o_{i t}+\beta_{5} b s_{i t}+\beta_{6} a g e_{i t}+\xi_{i t}$ (2) According to the employees number employed in industrial enterprises, heavy- polluting firms are divided into larger-size enterprises, medium-sized enterprises and smaller-size enterprises, and whether the change of firm size can adjust the impact of climate change on the financing cost of heavy-polluting firms. In order to investigate whether firm age can correct the impact of climate change on the financing cost of heavy-polluting firms according to Hypothesis 3 , we construct the following econometric model:

$D F C_{i t}=c+a_{1} C D_{i t} \times a g e_{i t}+a_{2} A T_{i t} \times a g e_{i t}+\beta_{7} Q_{i t}+\beta_{2}$ size $_{i t}+\beta_{3}$ grow $_{i t}+\beta_{4} g s_{i t}+\beta_{5} c o_{i t}+\beta_{6} b s_{i t}+\xi_{i t}$ (3) Heavy-polluting firms are divided into younger firms and older firms, and whether firm age will correct the impact of climate change on the financing costs of heavy-polluting firms.

\section{2 definition of relevant variables}

Debt financing cost is defined by the difference both net capital expenditure and interest income divided by the sum of short-term and long-term debt, used as the measure of debt financing costs of heavypolluting firms. Greater debt financing costs imply the higher interest expenditure, conversely, lower debt financing cost imply lower interest expenditure of heavy-polluting firm's debt.

Climate change is to measure regional climate change on the basis of the annual average temperature change ratio and annual precipitation change ratio in these cities that heavy-polluting firms are registered. The annual average temperature change ratios of heavy-polluting firms are calculated by the difference both the average temperature of the current year and the average temperature of the previous year and then divided by the average temperature of the previous year, which are used to measure the annual average temperature change. The annual precipitation change ratios of the heavy-polluting firms are calculated by the precipitation difference both current year and previous year and then divided the precipitation of the previous year, which are used to measure the annual precipitation change. The greater temperature change ratio and precipitation change ratios reflect greater climate change in these regions, conversely, the lower temperature change ratio and the precipitation change rate reflect the smaller climate change range in these regions.

The control variables mainly include market value, firm size, firm growth, tangible assets ratios, ownership concentration, board of director size and firm age. The firm market value is defined as the market value of heavy-polluting firm divided by the replacement cost of assets, measure by Tobin Q value. The greater Tobin Q value imply higher market value and good investment opportunities of heavy- 
polluting firms, and lower debt financing cost; On the contrary, the smaller Tobin Q value imply lower market value and poor investment opportunities, and higher debt financing cost. The firm size is defined as the natural logarithm of the number of employees in heavy-polluting firms; larger heavy-polluting firm size reflects the lower debt financing cost, conversely smaller firm size reflects higher debt financing cost. The heavy-polluting firm growth is calculated by the difference of sales revenue both current year and previous year, and then divided by the sales revenue in the previous year. The ratio of tangible assets is calculated by the ratio of tangible assets value to total assets value of heavy-polluting firms. The ownership concentration is calculated by the sum of shareholding ratios of the five largest shareholders. The firm age is calculated by the difference both current date and initial public offering date, and then divided by 365 .

Table 1

Definitions of related variables

\begin{tabular}{|c|c|c|c|}
\hline $\begin{array}{l}\text { Variable } \\
\text { property }\end{array}$ & $\begin{array}{l}\text { Variable } \\
\text { Symbol }\end{array}$ & Variable Name & Variable calculation method \\
\hline \multirow{2}{*}{$\begin{array}{l}\text { Explained } \\
\text { variable }\end{array}$} & \multirow[t]{2}{*}{$\mathrm{DFC}_{\text {it }}$} & Debt financing & \multirow[t]{2}{*}{ (net capital expenditure-interest income)/total debt } \\
\hline & & Cost & \\
\hline \multirow[t]{2}{*}{$\begin{array}{l}\text { Explanatory } \\
\text { variable }\end{array}$} & $\mathrm{CD}_{\text {it }}$ & $\begin{array}{l}\text { Annual average } \\
\text { temperature } \\
\text { change rate }\end{array}$ & $\begin{array}{l}\text { average temperature of current year-average } \\
\text { temperature of previous year)/average temperature } \\
\text { of previous year }\end{array}$ \\
\hline & $A T_{i t}$ & $\begin{array}{l}\text { Annual } \\
\text { precipitation } \\
\text { change rate }\end{array}$ & $\begin{array}{l}\text { (precipitation of current year- precipitation of } \\
\text { previous year) / precipitation of previous year }\end{array}$ \\
\hline \multirow{7}{*}{$\begin{array}{l}\text { Control } \\
\text { variable }\end{array}$} & $\mathrm{Q}_{\text {it }}$ & Market value & market value/asset replacement cost \\
\hline & size $_{i t}$ & Enterprise scale & natural logarithm of the number of firm employees \\
\hline & grow $_{\text {it }}$ & Enterprise growth & $\begin{array}{l}\text { (sales revenue of current year-sales revenue of } \\
\text { previous year)/sales revenue of previous year }\end{array}$ \\
\hline & $\mathrm{gs}_{\mathrm{it}}$ & $\begin{array}{l}\text { Tangible assets } \\
\text { ratio }\end{array}$ & tangible assets value/total assets value \\
\hline & $\mathrm{Co}_{\text {it }}$ & $\begin{array}{l}\text { Ownership } \\
\text { Concentration }\end{array}$ & $\begin{array}{l}\text { The sum of shareholding ratios of the five largest } \\
\text { shareholders }\end{array}$ \\
\hline & $b s_{i t}$ & $\begin{array}{l}\text { Board of directors } \\
\text { size }\end{array}$ & natural logarithm of board of directors \\
\hline & age $_{i t}$ & Firm age & (current date-initial public offering date)/365 \\
\hline
\end{tabular}

\section{Data Sources And Descriptive Statistics}

\subsection{Data sources}


The identification of heavy-polluting industries is based on "Classified Management List of Environmental Protection Verification Industries of Listed firms" ([2008] No.373) formulated by the Chinese Ministry of Ecology and Environment in 2008. Here heavy-polluting industries cover 18 types of heavy-polluting industries such as thermal power, steel, cement, electrolytic aluminum, coal, metallurgy, chemical industry, petrochemical industry, building materials, paper making, brewing, pharmacy, fermentation, textile, leather making and mining etc. Among them, there are 44 samples in mining industry, 287 samples in chemical industry, 31 samples in ferrous metal smelting industry, 103 samples in non-ferrous metal industry, 63 samples in building materials industry, 36 samples in beverage manufacturing industry and condiment fermentation industry, 49 samples in textile manufacturing industry and paper industry, 114 samples in chemical pharmaceutical and biological products industry, 48 samples in thermal power, thermal power and gas industry and 14 samples in other heavy-polluting industries. In this paper, the whole samples are delete $S T^{\star}$, missing and anomalies firm data, and finally collect 789 heavy-polluting firms.

The research period covers 11 years from 2008 to 2018, with 8679 total valid observations. The original data of relevant variables come from the following ways: The original data of relevant variables such as debt financing cost, market leverage, firm scale, firm growth, tangible asset ratio, ownership concentration and firm age in heavily polluting industries come from Tong-Hua-Shun financial database, Tobin $Q$ value comes from China Stock Market and Accounting Research(CSMAR) database, The annual average temperature and annual rainfall data come from the Global Statistical Data Analysis Platform (EPS), China Meteorological Database and Chinese Yearbook of CNKI Database. The data are manually collected according to the annual average temperature and annual rainfall data of heavy-polluting firms where are registered cities. The board size comes from WIND Financial Database. The Notice on the Classification Standards of Small-size and Medium-sized firms issued by the National Development and Reform Commission, the National Bureau of Statistics, the Ministry of Industry and Information Technology and the Ministry of Finance, and the Measures for the Classification of Large, Medium and Small firms in Statistics formulated by the National Bureau of Statistics in China point out that the number of employees in large-size enterprises are more than 1,000, the number of employees in mediumsized firms are between 300 and 1,000, the number of employees in small-size firms are between 20 and 300 , and the number of employees in micro firms are less than 20 . According to the number of employees in heavy-polluting industrial firms, this paper divides total firms into large-size firms (with 1,000 employees), medium-sized firms (300 1000 employees) and small-size firms (less than 300 employees). According to firm's age, this paper divides heavy-polluting firms into younger firms (firm age $<5$ years) and older firms (firm age 5 years).

\subsection{Descriptive statistics}

Table 2 shows the descriptive statistics of financing costs, temperature changes and precipitation changes of different types of heavy-polluting firms. The average of financing costs of large-size, mediumsize and small-size heavy-polluting firms are $0.1280,0.1929$ and 0.2348 respectively, and their standard deviations are $0.3027,0.3574$ and 0.5284 respectively. With the gradual increase of firm scale, the 
financing costs of heavy-polluting firms show a gradual downward trend, and the differences of firms' financing costs also exhibit a gradual downward trend. The average annual temperature changes of large-size, medium-size and small-size heavy-polluting firms are $-0.0001,-0.0003$ and -0.0003 respectively, and their standard deviations are $0.0485,0.0436$ and 0.0395 respectively. With the gradual increase of firm scale, the average annual temperature changes of heavy-polluting firms indicate slight changes, but the differences of temperature changes show a gradual narrowing trend. The average annual precipitation changes of large-size, medium-size and small-size heavy-polluting firms are $0.0527,0.0478$ and 0.0445 respectively, and their standard deviations are $0.3031,0.2744$ and 0.2633 respectively. With the gradual increase of firm scale, the annual precipitation changes of heavy-polluting firms show a gradual downward trend, and the differences of precipitation changes also show a gradual downward trend. According to firm age, the debt financing costs of younger and older firms are 0.2267 and 0.1105 respectively, and their standard deviations are 0.4791 and 0.3312 respectively. With an increase of firm age, the financing costs of heavy- polluting firms have a gradual downward trend, and the differences in financing costs of heavy-polluting firms also have a downward trend in the period. The average annual temperature changes of younger and older heavy-polluting firms are -0.0004 and -0.0001 respectively, and their standard deviation are 0.0372 and 0.0535 respectively. With an increase of firm age, the annual temperature of younger and older heavy-polluting firms have a slight change trend, and the difference of annual temperature has a gradual enlargement trend. The average annual precipitations both younger and older heavy-polluting firms are 0.0473 and 0.0507 respectively, and their standard deviations are 0.2722 and 0.2999 respectively. With an increase of firm age, the annual precipitation both younger and older heavy-polluting firms tend to increase gradually, and the difference of annual precipitation also tends to enlarge gradually.

Table 2

Descriptive statistics of key variables of different-types heavy-polluting firms

\begin{tabular}{|c|c|c|c|c|c|c|}
\hline \multirow{2}{*}{$\begin{array}{l}\text { Variable } \\
\text { Statistics }\end{array}$} & \multicolumn{2}{|c|}{ Financing cost } & \multicolumn{2}{|c|}{ Air temperature change } & \multicolumn{2}{|c|}{ Variation of precipitation } \\
\hline & $\begin{array}{l}\text { Mean } \\
\text { value }\end{array}$ & $\begin{array}{l}\text { Standard } \\
\text { deviation }\end{array}$ & $\begin{array}{l}\text { Mean } \\
\text { value }\end{array}$ & $\begin{array}{l}\text { Standard } \\
\text { deviation }\end{array}$ & $\begin{array}{l}\text { Mean } \\
\text { value }\end{array}$ & $\begin{array}{l}\text { Standard } \\
\text { deviation }\end{array}$ \\
\hline $\begin{array}{l}\text { Large-size } \\
\text { firms }\end{array}$ & 0.1280 & 0.3027 & -0.0001 & 0.0485 & 0.0527 & 0.3031 \\
\hline $\begin{array}{l}\text { Medium-sized } \\
\text { firms }\end{array}$ & 0.1929 & 0.3574 & -0.0003 & 0.0436 & 0.0478 & 0.2744 \\
\hline $\begin{array}{l}\text { Small-size } \\
\text { firm }\end{array}$ & 0.2348 & 0.5484 & -0.0003 & 0.0395 & 0.0445 & 0.2633 \\
\hline Variable & \multicolumn{2}{|c|}{ Financing cost } & \multicolumn{2}{|c|}{ Air temperature change } & \multicolumn{2}{|c|}{ Precipitation } \\
\hline Statistics & $\begin{array}{l}\text { Mean } \\
\text { value }\end{array}$ & $\begin{array}{l}\text { Standard } \\
\text { deviation }\end{array}$ & $\begin{array}{l}\text { Mean } \\
\text { value }\end{array}$ & $\begin{array}{l}\text { Standard } \\
\text { deviation }\end{array}$ & $\begin{array}{l}\text { Mean } \\
\text { value }\end{array}$ & $\begin{array}{l}\text { Standard } \\
\text { deviation }\end{array}$ \\
\hline Younger firms & 0.2267 & 0.4791 & -0.0004 & 0.0372 & 0.0473 & 0.2722 \\
\hline Older firms & 0.1105 & 0.3312 & -0.0001 & 0.0535 & 0.0507 & 0.2999 \\
\hline
\end{tabular}




\section{Analysis And Discussion Of Empirical Results \\ 5.1 Hausman and F-tests}

Table 3 shows the statistical results of Hausman and F tests. In models 1, 2 and 3, the statistical values of Hausman test are 114.7000, 80.9700 and 178.1000 respectively, and their significance levels are significantly less than $1 \%$, rejecting the original hypothesis. The statistical values of $\mathrm{F}$ test are 2.5000 , 2.4400 and 2.6800 respectively, and their significance levels are significantly less than $1 \%$. Therefore, this paper conducts empirical analysis on models 1,2 and 3 using panel data analysis with the fixed effects.

Table 3

Statistical results of Hausman and $\mathrm{F}$ tests

\begin{tabular}{|llll|}
\hline Model & \multicolumn{2}{l}{ Hausman test } & F test \\
\cline { 2 - 4 } & Chi-Square Statistics & Chi-Square degree of freedom & F Statistics \\
\hline Model 1 & $114.7000^{\star \star \star}$ & 9 & $2.5000^{\star * \star}$ \\
\hline Model 2 & $80.9700^{\star \star \star}$ & 9 & $2.4400^{\star \star \star}$ \\
\hline Model 3 & $178.1000^{\star * \star}$ & 9 & $2.6800^{\star * \star}$ \\
\hline $\begin{array}{l}\text { Note: *** means that the statistic values both Hausman and F tests are significant at the } 1 \% \\
\text { significant level. }\end{array}$ & \\
\hline
\end{tabular}

\subsection{Empirical analysis of climate change and financing costs of heavy-polluting firms}

Table 4 shows the empirical results of the impacts of annual temperature and precipitation changes on the financing costs of heavy-polluting firms. In Model 1, the coefficient of annual temperature change to financing cost of heavy-polluting firms is 0.8396 , Temperature change can have a significant positive impact on the financing cost of heavy-polluting firm at the $5 \%$ significant level. It shows that the annual temperature change increases, the debt financing costs of heavy-polluting firms increase, continuous hot or severe cold will lead to high-load power consumption of heavy-polluting firms, the soaring price of fossil energy and the shortage of electricity supply cause productivity losses and increase production costs of heavy-polluting firms. Bank's lenders are worried that the continuous hot or severe cold cause certain operating efficiency and expected profits losses of heavy-polluting firms decline, and the risk of capital loans will increase, which will raise the debt financing costs of heavy-polluting firms. With the gradual deepening of China's carbon emission control and carbon trading mechanism, the continuous hot or severe cold prompt bank's lenders to pay more attention to the changes in environmental costs induced by fossil energy consumption and carbon emission control of heavy-polluting firms, which also raise the debt financing costs of heavy-polluting firms. The coefficients between annual precipitation change and financing cost of heavy-polluting firms is 0.1164 , and annual precipitation change have a significant positive impact on the financing cost of heavy-polluting firms at the $10 \%$ significant level. This 
shows that the sharp increase in annual precipitation may bring adverse impacts to heavy-polluting firms. For example, rainfalls inflow into warehouses and lead to accidental damage to inventory materials, and floods lead to traffic paralysis and production interruption, which bring short-term operating losses and profit decline to heavy-polluting firms, and debtors will increase debt financing costs because they bear the risk of accidental operating losses. Heavy polluting enterprises need to raise more external funds to improve the ability to market respond quickly and the protection of inventory materials, and then slow down the unexpected business losses induced by the sharp increase in precipitation.

Model 2 shows that the interaction coefficient between annual temperature change and enterprise scale is 0.1027 . Firm scale can adjust the positive relationship between temperature change and financing cost of heavy-polluting firms at the $5 \%$ significant level, and firm scale can also significantly adjust the positive relationship between precipitation change and financing cost of heavy-polluting firms at the $10 \%$ significant level. Compared with the annual temperature coefficient in model 1 , The interaction coefficient between firm scale and temperature change decreased greatly, this also indirectly shows that the positive impact of temperature change on financing cost of heavy-polluting firms tends to weaken with an increase of firm scale. The larger firm scale, the heavy-polluting firms with greater scale can resist the operational risks related to climate change, improve the market adaptability, mitigate the adverse effects of climate change on the operational risks of heavy -polluting firms, and reduce bank lenders' worries about the operational risks of heavy-polluting firms, and then obtain a certain degree of financing loan concessions. meanwhile, the interaction coefficient between firm scale and precipitation also shows a slight downward trend, the positive impact of precipitation changes on financing costs of heavy-polluting firms will be weakened with an increase of firm scale. The larger-scale heavy-polluting firms enhance their ability to resist the operational risks induced by the sharp increase in precipitation, and bank lenders' concerns about the operational risks, which is possible to reduce the financing costs of heavy-polluting firms.

Model 3 indicates that the interaction coefficient between annual temperature change and firm age is 0.0679, and firm age can adjust the positive relationship between temperature change and financing cost of heavy-polluting firms at the $10 \%$ significant level. Compared with model 1 , the interaction coefficient between firm age and temperature change decreases significantly, the positive impact of temperature change on the financing cost of heavy-polluting firms also shows a weakening trend with an increase of firm age. Moretime, the interaction coefficient between annual precipitation change and firm age is 0.0106 , and firm age can adjust the positive relationship between precipitation change and financing cost of heavy-polluting firms at the $10 \%$ significant level. Compared with Model 1, the impact of precipitation change on financing costs of heavy-polluting firms slows down the rising trend with an increase of firm age. Older heavy-polluting firms can improve their market adaptability to climate change, reduce the adverse operational risks induced by climate change, alleviate bank lenders' worries about the expected operational risks of heavy-polluting firms, and reduce the pressure of climate change on the rising financing costs of heavy-polluting firms. 
Moreover, the tangible assets ratio and ownership concentration have a significant positive impact on the financing cost of heavy-polluting firms at the $5 \%$ significant level, extreme climate change induces heavypolluting firms to enhance their strategic awareness and improve their ability coping with enterprise changes. More funds raised by heavy-polluting firms invest more physical assets to resist climate change, and then mitigate operational risks induced by climate change. Heavy -polluting firms with higher ownership concentration reduce the pressure from external stakeholders, improve the market response speed of organizations and reduce the operational risks induced by climate change. Therefore, tangible assets and ownership concentration reduce the financing costs of heavy-polluting firms. The larger and older heavy-polluting firms can enhance their adaptability adapting to climate change, enhance their market response speed to climate risks, and slow down the pressure of climate change on the rising financing costs of heavy-polluting firms.

Table 4 Empirical results of climate change and financing costs of heavy-polluting firms 


\begin{tabular}{|c|c|c|c|}
\hline Variable & Model 1 & Model 2 & Model 3 \\
\hline \multirow[t]{2}{*}{ C } & $0.2373^{\star \star \star}$ & $0.1342^{\star \star \star}$ & $0.1757^{\star \star \star}$ \\
\hline & $(5.4918)$ & $(8.4826)$ & (8.9111) \\
\hline \multirow{2}{*}{$C D_{i f}$} & $0.8396^{\star *}$ & & \\
\hline & (1.9690) & & \\
\hline \multirow{2}{*}{$A T_{\text {if }}$} & $0.1164^{*}$ & & \\
\hline & (1.9549) & & \\
\hline \multirow{2}{*}{$C D_{i t} \times s i z e_{i t}$} & & $0.1027^{\star \star}$ & \\
\hline & & (1.9788) & \\
\hline \multirow[t]{2}{*}{$A T_{i t} \times s i z e_{i t}$} & & $0.0079^{*}$ & \\
\hline & & $(1.8234)$ & \\
\hline \multirow[t]{2}{*}{$C D_{i t} \times a g e_{i t}$} & & & $0.0679^{\star}$ \\
\hline & & & (1.8439) \\
\hline \multirow[t]{2}{*}{$A T_{i t} \times a g e_{i t}$} & & & $0.0106^{*}$ \\
\hline & & & (1.7397) \\
\hline \multirow{2}{*}{$Q_{i t}$} & 0.0035 & $0.0082^{\star \star \star}$ & $0.0076^{\star \star \star}$ \\
\hline & (1.9549) & (3.8142) & $(3.4114)$ \\
\hline \multirow[t]{2}{*}{$s i z e_{i t}$} & $-0.0304^{\star \star \star}$ & & $-0.0036^{*}$ \\
\hline & $(-4.8970)$ & & $(-1.0519)$ \\
\hline \multirow{2}{*}{$g r o w_{i t}$} & -0.0216 & -0.0035 & 0.0148 \\
\hline & $(-0.7560)$ & $(-0.2235)$ & $(0.9370)$ \\
\hline \multirow{2}{*}{$G S_{i t}$} & $0.2383^{\star \star}$ & $0.1057^{\star \star \star}$ & $0.1268^{\star \star \star}$ \\
\hline & $(2.2145)$ & $(9.2021)$ & (11.0302) \\
\hline \multirow[t]{2}{*}{$C O_{i t}$} & $0.0943^{\star \star \star}$ & $0.0811^{\star \star \star}$ & $0.1426^{\star \star \star}$ \\
\hline & $(2.8509)$ & $(3.0200)$ & $(5.1838)$ \\
\hline \multirow{3}{*}{$B S_{i t}$} & $0.0315^{\star \star}$ & $0.0149^{* \star}$ & $-0.0551^{\star \star \star}$ \\
\hline & $(2.2145)$ & $(1.3500)$ & $(-4.9530)$ \\
\hline & $-0.0065^{\star \star \star}$ & $-0.0097^{\star \star \star}$ & \\
\hline
\end{tabular}




\begin{tabular}{|llll|}
\hline$C D_{\text {it }}$ & $(-6.4876)$ & $(-11.9948)$ & \\
\hline Fixed effect & Sectional fixation effect & Sectional fixation effect & Sectional fixation effect \\
\hline AR (2) & 0.0432 & 0.0399 & 0.0168 \\
\hline Sargan Test & 2.0790 & 1.0531 & 2.7002 \\
& $(0.5562)$ & $(0.3048)$ & $(0.1003)$ \\
\hline
\end{tabular}

Note: The values in the parentheses are T statistic value in GMM method; AR (2), Sargan Test statistics are $p$ values in parentheses; $* \star \star, * \star *$ indicate passing the test at the significant level of $1 \%, 5 \%$, and $10 \%$, respectively.

According to the firm scale division standard, this paper divides 789 heavy-polluting firms into large-size, medium-size and small-size heavy-polluting firms, and makes an empirical analysis on Model 1. Table 5 indicates the empirical effects of climate change on the financing cost of heavy-polluting firms under different firm scales. The coefficients of both annual temperature change and financing cost of large-size, medium-size and small-size heavy-polluting firms are $0.6284,0.7425$ and 1.1446 respectively.

Temperature change have a significant positive correlation with the financing cost of large-size, mediumsize and small-size heavy-polluting firms at the $10 \%$ significant level, and the positive impact of temperature change on the financing cost of heavy-polluting firms shows a significant downward trend with the increase of firm scale, and this result supports hypothesis 2 . The positive influence of temperature change on the financing cost of heavily polluting enterprises is gradually weakened with the increase of firm scale. The heavily polluting firms with greater firm scale strengthen their resistance to climate risks induced by temperature changes, enhance their strategic awareness coping with extreme temperature changes, improve their market response ability to extreme temperature changes, and weaken the influence of temperature changes on the financing costs of heavy-polluting firms. The coefficients of annual precipitation change on financing costs of large-size, medium-size and small-size heavy-polluting firms are $0.0251,0.2929$ and 0.3527 , respectively. The positive impact of annual precipitation on the financing cost of large-scale heavy polluting firms is not significant, However, the change of precipitation have a significant positive impact on the financing cost of medium-sized and small-size heavy polluting firms at the $5 \%$ significant level, and the positive impact of precipitation change on the financing cost of heavy-polluting firms also shows a gradual weakening trend with the gradual increase of firm scale. The larger heavy-polluting firms have the more diversified and multi-regional strategic pattern, the sharp increase of local precipitation have relatively less adverse impact on the financing activities, investment activities and business activities of larger heavy- polluting firms. On the contrary, the sharp increase of local precipitation have a greater impact on the expected business profits of small-size firms.

Table 5 Empirical impact of climate change on financing costs of heavy-polluting firms under different firm scales 


\begin{tabular}{|c|c|c|c|}
\hline \multirow[t]{2}{*}{ Variable } & \multicolumn{3}{|l|}{ GMM method } \\
\hline & Large-size firms & Medium-sized firms & Small-size firms \\
\hline \multirow[t]{2}{*}{$c$} & $-1.1433^{\star \star \star}$ & -0.4737 & -0.0132 \\
\hline & $(-5.6803)$ & $(-1.2622)$ & $(-0.4121)$ \\
\hline \multirow[t]{2}{*}{$C D_{i t}$} & $0.6485^{\star \star}$ & $0.7425^{\star \star}$ & $1.1446^{*}$ \\
\hline & $(2.0677)$ & $(2.3497)$ & $(1.6835)$ \\
\hline \multirow{2}{*}{$A T_{i t}$} & 0.0251 & $0.2929^{\star \star}$ & $0.3537^{\star \star \star}$ \\
\hline & $(0.8671)$ & $(2.4361)$ & (3.2290) \\
\hline \multirow{2}{*}{$Q_{i t}$} & 0.0056 & 0.0056 & $0.0423^{\star \star \star}$ \\
\hline & $(1.3133)$ & $(-1.0479)$ & $(4.0151)$ \\
\hline \multirow{2}{*}{$s i z e_{i t}$} & $0.1593^{\star \star \star}$ & 0.0212 & $0.0428^{\star \star \star}$ \\
\hline & $(8.3666)$ & $(0.5238)$ & $(7.5965)$ \\
\hline \multirow{2}{*}{ grow $_{i t}$} & $-0.0697^{\star \star \star}$ & -0.0441 & $-0.1643^{\star \star}$ \\
\hline & $(-2.6028)$ & $(-0.8688)$ & $(-2.0940)$ \\
\hline \multirow[t]{2}{*}{$G S_{i t}$} & $0.0912^{\star \star}$ & $0.0449^{*}$ & $0.0301^{\star \star \star}$ \\
\hline & $(2.6023)$ & $(1.6032)$ & $(3.2962)$ \\
\hline \multirow{2}{*}{$C O_{i t}$} & $0.2171^{\star \star}$ & $0.3617^{\star \star \star}$ & 0.0733 \\
\hline & $(3.0546)$ & (3.0695) & $(1.5467)$ \\
\hline \multirow{2}{*}{$B S_{i t}$} & -0.0345 & 0.2060 & $-0.0480^{\star \star}$ \\
\hline & $(-0.4923)$ & $(1.5428)$ & $(-2.3855)$ \\
\hline \multirow[t]{2}{*}{$a g e_{i t}$} & $-0.0124^{\star \star \star}$ & $-0.0114^{\star \star}$ & $-0.0387^{\star \star \star}$ \\
\hline & $(-6.7344)$ & $(-2.0793)$ & $(-7.0547)$ \\
\hline
\end{tabular}

Fixed effect Sectional fixed effect Sectional fixed effect Sectional fixed effect

$\begin{array}{llll}C D_{i f} & 0.1516 & 0.2677 & 0.2097\end{array}$

\begin{tabular}{llll} 
AR $(2)$ & 0.0550 & 0.1792 & 0.1194 \\
\hline Sargan Test & 2.2102 & 2.0501 & 1.9367 \\
& $(0.2991)$ & $(0.3259)$ & $(0.5293)$
\end{tabular}


Note: The values in the parentheses are T statistic value in GMM method; AR (2), Sargan Test statistics are $p$ values in parentheses; $* \star \star, * *, *$ indicate passing the test at the significant level of $1 \%, 5 \%$, and $10 \%$, respectively.

In Table 6, Cccording to firm age of heavy-polluting firms, this paper divides heavy-polluting firms into younger and older firms, and makes an empirical analysis of model 1 , and the empirical impacts of climate change on the financing costs of heavy- polluting enterprises under different firm age. The coefficients of annual temperature change on the financing cost of younger and older heavy-polluting firms are 0.8635 and 0.2017 respectivly. Temperature change have a significant positive impact on the financing cost of younger and older heavy-polluting firms at the $10 \%$ significant level, and the positive impact of temperature change on younger heavy-polluting firms is more significant, this result supports hypothesis 3 . Moreover the annual precipitation changes have a significant positive impact on the financing cost of younger heavy- polluting firms at the $10 \%$ significant level, while they have no significant impact on the financing cost of older heavy-polluting firms.

Table 6: Empirical impact of climate change on financing costs of heavy-polluting firms under different firm ages 


\begin{tabular}{|c|c|c|}
\hline \multirow[t]{2}{*}{ Variable } & \multicolumn{2}{|l|}{ GMM method } \\
\hline & Younger firms & Older firms \\
\hline \multirow[t]{2}{*}{$c$} & $0.1980^{\star \star \star}$ & 0.1776 \\
\hline & $(4.5568)$ & $(0.5010)$ \\
\hline \multirow{2}{*}{$C D_{i t}$} & $0.8635^{\star \star}$ & $0.2017^{\star}$ \\
\hline & $(1.9137)$ & $(1.5994)$ \\
\hline \multirow{2}{*}{$A T_{\text {it }}$} & $0.0668^{*}$ & 0.0185 \\
\hline & (1.7822) & $(0.6758)$ \\
\hline \multirow{2}{*}{$Q_{i t}$} & 0.0136 & $0.0160^{\star}$ \\
\hline & $(1.0517)$ & $(1.8570)$ \\
\hline \multirow{2}{*}{$s i z e_{i t}$} & $-0.0457^{\star \star \star}$ & $-0.0461^{\star *}$ \\
\hline & $(-3.7595)$ & $(-2.2771)$ \\
\hline \multirow{2}{*}{ grow $_{i t}$} & $-0.0504^{\star \star}$ & 0.1393 \\
\hline & $(-2.2976)$ & $(1.4622)$ \\
\hline \multirow{2}{*}{$G S_{i t}$} & $0.6888^{\star \star \star}$ & $0.0146^{\star \star}$ \\
\hline & (11.9242) & $(2.4334)$ \\
\hline \multirow{2}{*}{$C O_{i t}$} & $0.2598^{\star \star}$ & $0.5779^{\star \star \star}$ \\
\hline & $(2.0869)$ & $(6.2064)$ \\
\hline \multirow{2}{*}{$B S_{i t}$} & $-0.0684^{\star \star \star}$ & 0.0156 \\
\hline & $(-2.9912)$ & $(0.1109)$ \\
\hline \multirow{2}{*}{$a g e_{i t}$} & $-0.0095^{\star *}$ & -0.0032 \\
\hline & $(-2.4684)$ & $(-1.3406)$ \\
\hline Fixed effect & Sectional fixed effect & Sectional fixed effect \\
\hline C & 0.2456 & 0.0849 \\
\hline AR (2) & 0.1602 & 0.1081 \\
\hline \multirow[t]{2}{*}{ Sargan Test } & 1.9635 & 2.2152 \\
\hline & $(0.4515)$ & $(0.3383)$ \\
\hline
\end{tabular}


Note: The values in the parentheses are T statistic value in GMM method; AR (2), Sargan Test statistics are $p$ values in parentheses; $\star \star \star, ~ * \star, *$ indicate passing the test at the significant level of $1 \%, 5 \%$, and $10 \%$, respectively.

\section{Conclusion And Policy Implications}

Extreme climate changes may induce related climate risks and influence the financing decision-making behavior, resource allocation efficiency of heavy-polluting enterprises. Extreme climate changes also have an important impact on investment and business activities and expected operating income of heavypolluting firms. Because there are certain financial frictions, information asymmetry and financing discrimination in the financial market, financial institutions have corresponding credit discrimination and unfair distribution of credit resources for different types of heavy-polluting firms. This article selects 789 heavy-polluting firms from 2010 to 2018, empirically analyzes the impact of annual temperature and precipitation changes on the financing costs of heavy-polluting firms using panel data analysis, and analyzes the significant influencing differences of climate change on the financing costs of heavypolluting firms under different types of firm scale and age.

The empirical results show that the annual temperature and precipitation changes have significant positive impacts on the financing cost of heavy-polluting firms at the $10 \%$ significant level. The increase of temperature and precipitation significantly increase the financing cost of heavy-polluting firms, and the firm size and firm age also significantly moderate the relationship between climate change and the financing cost of heavy-polluting firms. With the increase of firm scale, the impacts of annual temperature and precipitation changes on the financing costs of large-size, medium-size and small-size heavy-polluting firms gradually boost, especially the financing costs of small-size heavy polluting firms induced by climate change greatly increase. With the growth of firm age, the annual climate and precipitation changes gradually increase the financing costs of older and younger heavy-polluting firms, and climate change can significantly increase the financing costs of younger heavy- polluting firms. Moreover, higher tangible asset ratio and ownership concentration may increase the financing cost of heavy-polluting firms, while the firm size and firm age may reduce the financing cost of heavy-polluting firms.

The above empirical results confirm that climate changes have significant positive impacts on the financing cost of heavy-polluting firms, which are helpful for government decision-makers to identify the significant impacts of climate changes on the financing costs of heavy-polluting firms and for firm managers to identify the optimal impacts of climate changes on their financing costs. This paper puts forward the following relevant policy recommendations:

(1) Government decision-makers identify and optimize the transmission effect of climate changes on the financing behavior of heavy-polluting firms. Policies and governance actions to deal with climate change (such as carbon trading mechanism, energy-saving and emission-reduction policies, compensation system for ecological environment damage, etc.) directly affect the behavior of financing decisions, 
investment activities and business activities of heavy-polluting firms. Climate changes significantly increase the financing cost of heavy-polluting firms, Government decision-makers need to identify the transmission effects of climate changes on the financing decisions of heavy-polluting enterprises in different heavy industries, different types and different environmental regulation ways and intensities. We should optimize policies to deal with climate changes and their governance actions, reduce the adverse effects of climate changes and environmental regulations on the financing costs of heavy-polluting firms, and adopt regional differentiation strategies to promote the successful governance actions of heavypolluting firms to deal with climate changes.

(2) Local governments should Reduce financial market friction and financing discrimination, optimize the efficiency of financial resource allocation, and reduce the impacts of climate changes on financial resource allocation. The changes of temperature and precipitation have significant differentiated impacts on the financing costs of heavy-polluting firms with different firm size and firm age. These policies to deal with climate change have important impacts on the financing, investment, production and operation activities of heavy-polluting firms. Financial institutions may have certain market friction and financing discrimination in order to effectively control loan risks. The government promotes market competition of financial institutions, enhance the internal competitive structure and optimization of the banking system, establish financial resource allocation. Heavy-polluting firms with the response to climate change and climate risks may reduce financial market friction, reduce financing discrimination under firm scale, firm age and ownership types of heavy-polluting firms, promote the fairness of financial resource and reduce the financing costs of small-size and medium-sized heavy-polluting firms.

(3) Firm managers identify the significant impacts of climate changes on the financing, investment and production and operation activities of heavy-polluting firms, understanding the climate risks and operation risks may result in strategic actions to deal with climate changes, optimize the organizational structure, improve the strategic awareness and rapid response ability to adapt with climate change. Reducing the adverse effects of extreme climate change and governance actions to deal with climate change may bring to the production, operation, financing activities and expected operating profits of heavy-polluting firms, and comprehensively improve the strategic layout, organizational flexibility and rapid response capability of heavy-polluting firms to quickly respond to climate change.

\section{Declarations}

The following statements must be included in your submitted manuscript under the heading 'Statements and Declarations'.

Funding:The authors are grateful for the research support from the following foundations: the Shanghai Planing office of Philosophy and Social Science (2020BJB011); Shanghai Soft Science Foundation of Key Project "Science and Technology Innovation Actions" (21692108000); National Natural Science Foundation of China (71673236).

Ethical Approval: The content of this manuscript has involved no ethical hazards. 
Declaration of interest statement: The authors have no relevant financial or non-financial interests to disclose. No conflict of interest exists in the submission of this manuscript, all authors accept that this manuscript is submitted to Journal of Cleaner Production. I would like to declare that this paper is our original unpublished work and it has not been submitted to any other journal.

Consent of publish: We approval the publish in Environmental Science and Pollution Research.

Authors Contributions: Yixia Nie finishes the data collection and provides the empirical results. Kai Chang finishes the research design and writes the content of the manuscript.

Availability of data and materials: All the availability of data and materials are shown in the manuscript, and data source can be obtained from the author if the scholars need them.

\section{References}

1. Amran A, Ooi SK, Nejati M, Zulkafli AH, Lim BA (2012) Relationship of firm attributes, ownership structure and business network on climate change efforts: evidence from Malaysia. Int J Sustain Dev World Ecol 19(5):406-414

2. Bakhsh K, Abbas K, Hassan S (2020) Climate change-induced human conflicts and economic costs in Pakistani Punjab. Environ Sci Pollut Res 27:24299-24311

3. Berkma.H., Jona.J.,Soderstrom.N.2019. Firm value and government commitment to combating climate change.Pacifc-Basin Finance Journal(53),297-307

4. Cadez.S.,Czerny.A.2016. Climate change mitigation strategies in carbon-intensive firms.Journal of Cleaner Production(112),4132-4143

5. Cadez.S.,Guilding.C.2017. Examining distinct carbon cost structures and climate change abatement strategies in CO2 polluting firms. Accounting Auditing \& Accountability Journal30(5),1041-1064

6. Cadez.S., Czerny.A.,Letmathe.P.2019.Stakeholder pressures and corporate climate change mitigation strategies.Business Strategy and the Environment28(1),1-14

7. Canevari LL 2020.Climate change adaptation in the private sector: application of a relational view of the firm.Climate and Development12(3),216-227

8. Chen B, Li H (2020) Impact of climate change and human activities on economic values produced by ecosystem service functions of rivers in water shortage area of Northwest China. Environ Sci Pollut Res 27:26570-26578

9. Clark CE, Crawford EP (2012) Influencing climate change policy: the effect of shareholder pressure and firm environmental performance. Business \& Society 51(1):148-175

10. Dahlmann F Branicki.L.,Brammer.S.2019.Managing carbon aspirations: the influence of corporate climate change targets on environmental performance.Journal of Business Ethics(158):1-24

11. Baumgartner DamertM.R.J (2018) External pressures or internal governance-what determines the extent of corporate responses to climate change.Corporate Social Responsibility and Environmental 
Management. (25):473-488

12. Eleftheriadis IM, Anagnostopoulou EG 2015.Relationship between corporate climate change disclosures and firm factors.Business Strategy and the Environment24(8),780-789

13. Giannarakis G, Zafeiriou EArabatzisG (2018) Determinants of corporate climate change disclosure for European firms. Corp Soc Responsib Environ Manag 25(3):281-294

14. Hiatt SR, Grandy JB 2015.Organizational responses to public and private politics: an analysis of climate change activists and US oil and gas firms.Organizational Science26(6),1869-1786

15. Hsu AW .T.2013. Does the market value corporate response to climate change.Omega(41),195-206

16. Kennard A (2020) The enemy of my enemy: when firms support climate change regulation. Int Org $74(2): 187-221$

17. Koomey J (2013) Moving beyond benefit-cost analysis of climate change. Environmental Research Letters 8(4):1-5

18. Kuo L, Yu HC (2015) The signals of green governance on mitigation of climate change - evidence from Chinese firms. Int J Clim Change Strateg Manag 7(2):154-171

19. Lee SY, Park YS (2015) Market responses to firms' voluntary climate change information disclosure and carbon communication. Corp Soc Responsib Environ Manag 22(1):1-15

20. Li A, Gao L, Chen S (2021) Financial inclusion may limit sustainable development under economic globalization and climate change. Environmental Research Letters 16(5):1-14

21. Li L, Liu Q, Tang DL et al (2017) Media reporting, carbon information disclosure, and the cost of equity financing: evidence from China. Environ Sci Pollut Res 24:9447-9459

22. Linnenluecke MK, Stathakis A, Griffiths.A (2011) Firm relocation as adaptive response to climate change and weather extremes.Global Environmental Change(21),123-133

23. Linnenluecke MK, Griffiths A, Winn MI (2013) Firm and industry adaptation to climate change: a review of climate adaptation studies in the business and management field. Wlley Interdisciplinary Reviews-Climate Change 4(5):397-416

24. Lu SB, Bai X, Li WWangN (2019) Impacts of climate change on water resources and grain production. Technological Forecasting \& Social Change 143:76-84

25. Lu SB, Zhang XL et al 2021.The energy-food-water nexus: Water footprint of Henan-Hubei-Hunan in China.Renewable andSustainable Energy Reviews135,1-12

26. Lu SB, Zhang XL (2020) Evolutionary analysis on structural characteristics of water resource system in basins of Northern China. Sustain Dev 28(4):800-812

27. Lucas EC, Silva.W MD (2018) Impact of climate on firm value: Evidence from the electric power industry in Brazil. Energy 153:359-368

28. Mahmood N, Arshad M et al (2020) Economic efficiency of rainfed wheat farmers under changing climate: evidence from Pakistan. Environ Sci Pollut Res 27:34453-34467

29. Mele M, Gurrieri AR, Morelli G et al (2021) Nature and climate change effects on economic growth: an LSTM experiment on renewable energy resources. Environ Sci Pollut Res 28:41127-41134 
30. Nohara D, Yoshida Y, Misumi,K.,Ohba M (2013) Dependency of climate change and carbon cycle on CO2 emission pathways. Environmental Research Letters 8(1):1-10

31. Nordhaus WD, Yang ZL .1996. A regional dynamic general-equilibrium model of alternative climatechange strategies. The American Economic Review, 86(4):741-765

32. Praveen.K.,Mohammad.F.2018. Impact of climate change disclosure on financial performance: an analysis of Indian firms.Journal of Environmental Accounting and Management6(3),185-197

33. Salvo MD, Begalli D, Capitello R Signorello.G.2015.A spatial micro-econometric approach to estimating climate change impacts on wine firm performance: A case study from Moldavia region,Romania. Agricultural Systems(141),48-57

34. Sarasini S 2013.Institutional work and climate change: Corporate political action in the Swedish electricity industry.Energy Policy( 56),480-489

35. Secinaro S, Brescia VCalandraD (2020) Impact of climate change mitigation policies on corporate financial performance: Evidence-based on European publicly listed firms. Corp Soc Responsib Environ Manag 27(6):2491-2501

36. Sequeira TN, Santos MS (2018) Climate change and economic growth: a heterogeneous panel data approach. Environ Sci Pollut Res 23:22725-22735

37. Sullivan.R., Gouldson.A. The governance of corporate responses to climate change: an international comparison.Business Strategy and the Environment, (26),413-425

38. Tamošiūnas.A (2014) The model for evaluation of corporate strategic changes in the context of climate change: plywood manufacture. Journal of Business Economics and Management 15(1):135-152

39. Takakura J, Fujimori S, Takahashi K et al (2017) Cost of preventing workplace heat-related illness through worker breaks and the benefit of climate-change mitigation. Environmental Research Letters 12(6):1-13

40. Toft KH Rüdiger,M.2020. Mapping corporate climate change ethics: Responses among three Danish energy firms.Energy Research \& Social Science(59),1-17

41. Wang DD, Li SL ,T.2018. Determinants of climate change mitigation technology portfolio: An empirical study of major U.S. firms. Journal of Cleaner Production(196),202-215

42. Wang DD (2018) Climate change mitigation targets set by global firms: Overview and implications for renewable energy.Renewable and Sustainable Energy Reviews(94),386-398

43. Yu Y, Wang DD, Li SL, Shi QF (2016) Assessment of U.S. firm-level climate change performance and strategy. Energy Policy 92:432-443

44. Busch ZieglerA,T., Hoffmann.V.H (2011) Disclosed corporate responses to climate change and stock performance: An international empirical analysis. Energy Econ 33:1283-1294 